\title{
CTENANTHIDIUM,GEN.N. DE DIANTHIDIINI COM QUATRO ESPÉCIES NOVAS DA AMÉRICA DO SUL (HYMENOPTERA, MEGACHILIDAE) ${ }^{1}$
}

\author{
Danúncia Urban ${ }^{2}$
}

\begin{abstract}
CTENANTHIDIUM, GEN.N. OF DIANTHIDIINI WITH FOUR NEW SPECIES FROM SOUTH AMERICA (HYMENOPTERA, MEGACHILIDAE). Ctenanthidium, gen.n. is proposed to include four new neotropical species of Anthidiinae bees, Ctenanthidium gracile, sp.n. from Brazil (Paraná, Curitiba); Ctenanthidium argentinum, sp.n. from Argentina (Córdoba); Ctenanthidium bifasciatum, sp.n. from Uruguai (Colonia, La Estanzuela) and Ctenanthidium nigripes, sp.n. from Bolivia (Potosi, Casa Grande). The males are characterized by the border of the third sternum with an apical comb of strong bristles apically rounded, between lateral fringes.

KEY WORDS. Ctenanthidium, gen.n, Anthidiinae, Megachilidae, Hymenoptera, Taxonomy
\end{abstract}

\section{Ctenanthidium, gen.n.}

Espécie tipo Ctenanthidium gracile, sp.n.

Macho. Tegumento brilhante densamente marcado por pontos grandes na cabeça e mesosoma, pouco menores nos tergos basais e mais reduzidos nos esternos. Pilosidade muito curta denso-plumosa nos mesepisternos e tergos distais, alongada nas paroculares junto às antenas e nos esternos; com cerdas lisas finas e alongadas em parte da fronte e no vértice (semi-decumbentes para a frente), no mesoscuto e escutelo; curtíssima nos tergos basais; no terceiro esterno com franjas látero-apicais longas e medianamente com franja marginal de cerdas grossas arredondadas na ponta e mais curtas que as franjas laterais. Mandíbulas tridentadas, os dentes equidistantes, com a carena externa-superior quase unida à látero-external, a interna-inferior só no terço apical e a externa-inferior até o meio, na metade basal com pontos grandes irregulares dando um aspecto rugoso e a pontuação bem mais reduzida para o ápice (após a carena látero-external). Palpos maxilares bi-articulados, o artículo basal muito curto e o apical alongado e com pêlos alongados na ponta. Clípeo quase achatado, deprimido no ápice, sem tubérculos na margem apical porém com emarginação média fraca, sobressaindo à base do labro; suturas subantenais fracamente arqueadas; carenas interalveolares fortes e laminadas, a lâmina um pouco projetada sobre o bordo interno do alvéolo antenal, tão afastadas na área

1) Contribuição número 765 do Departamento de Zoologia, Universidade Federal do Paraná.

2) Departamento de Zoologia, Universidade Federal do Paraná, Caixa Postal 19020, 81531-970 Curitiba, Paraná, Brasil. 
supraclipeal quanto seu comprimento e mais separadas na fronte; sem carena frontal; com carenas paroculares; genas largas diminuindo muito em direção às mandíbulas; carena hipostomal forte. Antenas com o escapo mais longo que a distância interalveolar, três flagelômeros basais mais curtos que seu diâmetro, os restantes um pouco mais longos.

Pronoto com lâmina translúcida para cima nos lobos, um pouco arqueada em direção ao mesoscuto porém terminando bem antes da sutura. Mesepisternos com carena pré-episternal no terço dorsal. Mesoscuto expandido aos lados em lâmina muito curta voltada para cima; escutelo arredondado posteriormente, com pequena emarginação mediana, expandido em lamela aos lados desta emarginação e sobressaindo ao metanoto; base do escutelo deprimida e brilhante entre as axilas, fracamente dividida no meio; axilas curtas, não projetadas para trás; tégulas arredondadas posteriormente sem emarginação.Asas anteriores com a bifurcação entre a média e a cubital coincidindo com a transversal cúbito-anal; asas posteriores com o lobo jugal mais longo que um terço do lobo anal; tarsômeros com pilosidade normal; com arólio entre as garras. Propódeo vertical com fovéolas basais maiores que o comprimento do metanoto, espiráculo propodeal carenado com larga área posterior brilhante foveolada e limitada por carena.

Tergos com depressão marginal estreita só nos flancos; sexto quase vertical com a depressão marginal completa e formando medianamente uma pequena projeção angulosa (brilhante posteriormente); sétimo disposto ventralmente e voltado para a frente,apicalmente com recorte raso no meio, orlado por duas projeções arredondadas e carenadas fracamente, não achatado, e com larga área expandida em direção ao sexto esterno. Esterno basal com carena mediana no terço basal e subapicalmente inflado; segundo inflado subapicalmente; terceiro longo, projetado para trás em arco; quarto com o bordo reto e parcialmente escondido pelo terceiro, com carena ântero-posterior bem nos flancos; quinto mais curto, com recorte apical em ângulo muito aberto, com carena como as do quarto porém projetada para trás em pequeno dente; sexto com bordo levemente bi-sinuoso e marcado por uma estreita dobra vertical do tegumento, posterior ao grádulo e mais afastada do mesmo nos lados

Fêmea semelhante ao macho, difere nas estruturas a seguir relacionadas: mandíbulas com quatro dentes apicais rasos, com carenas látero-external e externa inferior até o meio; com depressão marginal estreita nos flancos do primeiro ao quinto tergo; sexto tergo sem carena mediana, um pouco deprimido no disco e elevado para o ápice; sexto esterno normal; pernas normais, com arólio, lado externo das tíbias medianas com projecão espiniforme apical curta; pilosidade dos mesepisternos difere da do macho, fina, curta e lisa com poucos pêlos plumosos de permeio.

Comentário. Este gênero distingue-se dos demais Dianthidiini pela pontuacão grossa e densa, um pouco reduzida nos tergos e mais ainda nos esternos; carenas interalveolares fortes, laminadas e arqueadas, cobrindo parte dos alvéolos antenais; lobos pronotais com lâmina para cima, um pouco arqueada; com arólio; escutelo projetado em lâmina e fovéolas alongadas 
grandes na base do propódeo. Macho com o terceiro esterno mais longo no meio, recobrindo parcialmente o seguinte, com franjas longas látero-apicais e no meio uma série de cerdas grossas e mais curtas que os pelos das franjas; quinto esterno bem mais curto e o sexto com uma dobra do tegumento posterior ao grádulo, em ângulo muito aberto e revestida com pelos curtos (em degrau); sexto tergo deprimido no bordo, este laminado porém a lâmina voltada para trás e medianamente projetada em pequena angulosidade para cima (lisa e brilhante posteriormente); sétimo tergo fracamente bi-sinuado apicalmente porém inflado (não achatado). Fêmea com mandibula quadridentada com grossa pontuação na metade basal. Ctenanthidium gen.n. tem em comum com Anthidulum a projecão médio-apical angulosa no sexto tergo, terceiro esterno alongado, carena ântero-posterior bem nos flancos do quarto e quinto esternos projetada para trás em pequeno dente no quinto, o sulco escuto-escutelar com pequena separação mediana, porém o sétimo tergo de Anthidulum com o bordo medianamente projetado em arco e lateralmente em duas pequenas projeções digitiformes, carenas interalveolares muito fracas, além da ausência de arólio nas fêmeas separam estes dois gêneros. Na chave apresentada por Michener em 1948 entraria nos ítens finais, com Anthodioctes porém distinto à primeira vista pela ausência de carena pré-ocipital e de carena forte no primeiro tergo, pela lâmina translúcida dos lobos pronotais e pelos esternos modificados.

Etimologia. Ctenanthidium refere-se ao pente cerdoso do terceiro esterno do macho.

\section{Chave para as espécies de Ctenanthidium}

1. Machos 2

- Fêmeas 3

2. Mesoscuto fosco, com densa micro-pontuação nos pontos grandes e nos intervalos. Tegumento amarelo da cabeça misturado com ferrugíneo. Brasil (Paraná) gracile

- Mesoscuto brilhante, embora com micro-pontuação nos pontos grandes. Tegumento amarelo na cabeça sem mescla com ferrugíneo, exceto na faixa da metade posterior do vértice. Argentina (Córdoba, S.Luis) ..... argentinum

3. Mesoscuto preto, sem nódoas amarelas, fosco. Axilas e escutelo pretos, sem orla translúcida clara. Somente dois tergos com faixa amarela completa. Uruguai (Colonia) bifasciatum

- Mesoscuto brilhante ou fosco, com nódoas amarelas. Axilas e escutelo com nódoas amarelas e com orla translúcida levemente amarelada. Dois ou mais tergos com faixa amarela 
- Mais de dois tergos com faixa amarela discal 5

5. Vértice preto, somente com nódoa amarela acima dos olhos compostos. Pernas enegrecidas, sem áreas amarelo-ferrugíneas. Bolívia (Potosi) nigripes

- Metade posterior do vértice com larga faixa amarelo-ferrugínea até as pós-genas. Pernas com grandes áreas amarelo-ferrugíneas e pretas

gracile

\section{Ctenanthidium gracile, sp.n.}

Figs 1-7

Diagnose. Macho com o tegumento do mesoscuto com densa micro-pontuação resultando um aspecto fosco tanto nos intervalos como na maioria dos pontos, no escutelo a micro-reticulação somente nos intervalos e nos mesepisternos mais esparsa ainda; com faixa amarela discal larga no primeiro tergo e do terceiro ao quinto, mais estreita nos flancos destes; cabeça em grande parte amarela, com faixa amarelo-ferrugínea na área posterior do vértice até as pós-genas. Fêmea com área amarela parocular ultrapassando superiormente o nível dos alvéolos antenais; área amarelo-ferrugínea na metade posterior do vértice e tegumento fosco no mesosoma como no macho; com mais de duas faixas amarelas nos tergos.

Holótipo macho. Tegumento predominante preto com as seguintes áreas claras: amarelo no lado externo das mandíbulas, exceto os dentes e as margens; amarelo no clípeo, área supraclipeal, parte da fronte junto às carenas interalveolares e paroculares, tendendo para amarelo-ferrugíneo na base do clípeo, parte da fronte e paroculares superiores onde toma forma de estria, diminuindo para o vértice; parte posterior do vértice e pós-genas mais ferrugíneas; antenas com os quatro artículos basais ferrugíneos e os restantes castanhos escuros com áreas ferrugíneas. Pequena área amarelo-ferrugínea na parte ventral dos lobos pronotais, também desta côr faixas látero-basais no mesoscuto, um pouco prolongadas em estria fina e curta aos lados; tégulas mais ferrugíneas e axilas mais amarelas; margem posterior do escutelo amarelo-ferrugínea com orla translúcida acastanhada clara, também nas axilas.Pernas enegrecidas na coxa,trocânter e metade posterior dos fêmures posteriores, parte basal das coxas e algo nos trocânteres anteriores e medianos, restante amarelo-ferrugíneo.Asas escurecidas com veias enegrecidas.Tergo basal com faixa discal amarela muito larga, quase até a margem nos flancos e mais estreita no meio; do terceiro ao quinto faixa amarela larga dorsalmente e bem mais estreita nos flancos onde toma uma tonalidade um pouco ferrugínea; no sexto e sétimo faixa mais amarela ê ocupando a parte distal do tergo; nos cantos do segundo faixas amarelas discais curtas, não visíveis dorsalmente; esternos castanhos, os apicais de um amarelo acastanhado.

Pilosidade predominante branca, com cerdas acastanhadas finas e 
alongadas na metade dorsal da cabeça, mesoscuto e escutelo; pente cerdoso do terceiro esterno castanho.

Comprimento aproximado $5,83 \mathrm{~mm}$; comprimento da asa $5,08 \mathrm{~mm}$;largura da cabeça $2,16 \mathrm{~mm}$ e do metasoma $2,20 \mathrm{~mm}$; comprimento do olho $1,46 \mathrm{~mm}$; distância interorbital superior $1,40 \mathrm{~mm}$ e a inferior $1,06 \mathrm{~mm}$.
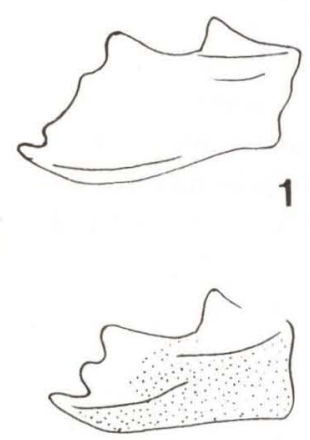

2

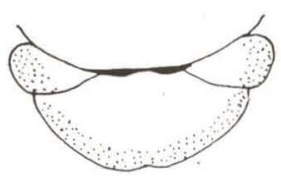

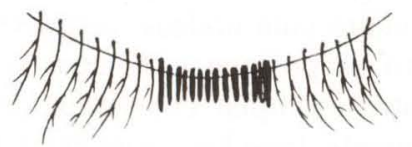

4

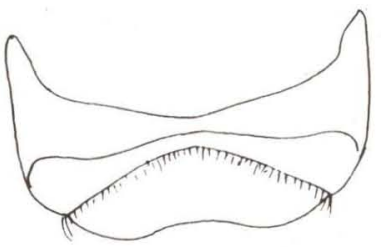

5

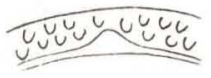

6

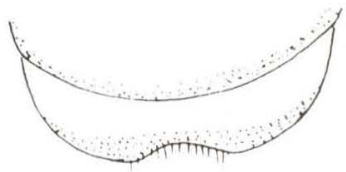

7

Figs 1-7. Ctenanthidium gracile, sp.n. (1) Mandibula da fêmea. Figs 2-7. Macho. (2) mandibula; (3) axilas e escutelo(com a metade do aumento); (4) ápice mediano do terceiro esterno; (5) sexto esterno; (6) ápice mediano do sexto tergo em vista posterior; (7) ápice do sétimo tergo em vista ventral. Em pontilhado tegumento amarelo-ferrugíneo.

Alótipo fêmea. Tegumento predominante preto, com área amarela nas paroculares inferiores até a sutura epistomal, estreitando em arco em direcão à área proximal das paroculares superiores e terminando bem acima dos alvéolos antenais; parte posterior do vértice e pós-genas amarelo-ferrugíneas; antenas com os cinco artículos basais amarelo-ferrugíneos. Pronoto com pequena área castanho-ferrugínea na parte ventral; mesoscuto com estreitas faixas láterobasais castanho-ferrugíneas; tégulas ferrugíneas; axilas amarelas e margem posterior do escutelo amarelo-ferrugínea com orla translúcida acastanhada clara, também nas axilas.Pernas enegrecidas até a parte basal do fêmur nas anteriores e medianas,o fêmur posterior inteiramente negro, demais áreas amarelo-ferrugem. Asas escurecidas, veias enegrecidas. Tergo basal com larga faixa discal amarela, mais estreita no meio e aumentando em direção à margem nos flancos; segundo e terceiro com larga faixa amarela discal, mais estreita nos cantos; quarto com a faixa amarela reduzida e mais estreita nos lados. 
Pilosidade lembra a do macho. Nos esternos cerdas lisas cremosas formando escopa.

Comprimento aproximado $5,83 \mathrm{~mm}$; comprimento da asa $5,42 \mathrm{~mm}$; largura da cabeça $2,26 \mathrm{~mm}$ e do metasoma $2,24 \mathrm{~mm}$; comprimento do olho $1,54 \mathrm{~mm}$; distância interorbital superior $1,44 \mathrm{~mm}$ e a inferior $1,18 \mathrm{~mm}$.

Variações. Machos com as faixas tergais amarelo-ferrugíneas ou castanho-ferrugíneas; segundo e terceiro esternos com margem estreita irregular amarela e primeiro com nódoas pequenas laterais amarelas; genas amarelo-ferrugem como as pós-genas. Fêmeas com o bordo posterior do escutelo ferrugíneo; outro exemplar com axilas, bordo do escutelo e faixas tergais castanhos levemente tingidos com ferrugíneo; uma fêmea com o tegumento das faixas tergais mais escurecido porém amarelado nas axilas e bordo do escutelo; e três exemplares com a faixa do quarto tergo interrompida no meio.

Holótipo macho, 1-I-1964, Curitiba; Paraná, Brasil, Laroca leg. Alótipo fêmea da mesma localidade e coletor, 14-X-1967. Parátipos - Curitiba: 2 fêmeas, IX-50 e X-1950, Moure leg.;1 macho, 20-X-63, Laroca e B.Cavanha leg.; 1 macho, 10-XI-63, Laroca leg.; 1 macho, 20-XI-63, Laroca leg.; 1 fêmea, 10-X-67, Laroca leg.; 1 macho 14-X-67, Laroca leg.; 2 fêmeas,18-X-67 e 2-XI-67, Laroca leg. S. José dos Pinhais, Paraná: 2 fêmeas 1-XII-62, Laroca leg. Piraquara, Paraná: 1 fêmea, XI-68, Moure, Mielke e Dairiki leg. Depositados na Coleção de Entomologia Pe.J.S. Moure, Departamento de Zoologia da Universidade Federal do Paraná.

Distribuição geográfica. Brasil: Paraná (Curitiba, S.J.dos Pinhais e Piraquara).

\section{Ctenanthidium argentinum, sp.n.}

Diagnose. Macho com o tegumento brilhante no mesoscuto, não fosco nem mesmo nos espaços entre os pontos, escutelo e mesepisternos brilhantes sem micro-reticulação. Tegumento da cabeça em grande parte amarelo, com faixa amarelo-ferrugínea na parte posterior do vértice; faixa amarela discal no primeiro tergo e do terceiro ao quinto. Fêmea com a nódoa amarela das paroculares quase até o vértice; pós-genas e parte posterior do vértice amarelo-ferrugíneas; com micro-reticulação nos espaços entre os pontos do mesoscuto porém o tegumento brilhante; somente primeiro e terceiro tergos com faixa amarela discal.

Holótipo macho. Tegumento preto da cabeça reduzido a uma grande área ocupando parte da fronte inclusive uma estria entre os alvéolos antenais, junto à sutura subantenal, parte superior das paroculares e metade anterior do vértice, as demais partes da face amarelas incluindo as mandibulas e as manchas paroculares que avançam até o vértice porém estreitando para o ápice junto aos olhos. Parte posterior do vértice e cantos superiores das pós-genas amarelo-ferrugíneos, restante das genas preto. Antenas com os quatro artículos 
basais amarelo-ferrugíneos por baixo, restante castanho. Mesosoma preto, lobo pronotal com pequena nódoa amarelo-ferrugínea; mesoscuto com estreita faixa amarela basal nos flancos, pouco mais larga para o meio; axilas e escutelo com larga margem posterior amarela, mais estreita no escutelo, ambos com orla translúcida acastanhada clara. Tégulas ferrugíneas; pernas anteriores com coxa e trocânter castanhos; nas médias o castanho até o meio do fêmur e nas posteriores o fêmur castanho (no parátipo grande área castanha nas tíbias), demais áreas amarelo-ferrugíneas. Asas escuras e veias enegrecidas. Tergos pretos, o basal com faixa discal amarela um pouco mais estreita no meio, nos flancos quase alcançando a margem; no segundo com nódoa amarela bem lateral prolongada para o dorso em faixa muito curta irregular; do terceiro ao quinto com faixa discal amarela, mais larga e com o bordo anterior bisinuoso no terceiro, estreitando muito para os lados; a faixa do quarto pouco mais estreita no meio e no mais como a do terceiro e a do quinto mais estreita que as anteriores; sexto e sétimo com faixa amarela apical estreita. Lados dos três esternos basais com manchas amarelas grandes, no segundo também nódoa médio-apical e no terceiro a nódoa médio-apical mais ferrugínea.

Pilosidade branca, pente cerdoso do terceiro esterno castanhoenegrecido.

Comprimento aproximado $5,42 \mathrm{~mm}$; comprimento da asa $5 \mathrm{~mm}$; largura da cabeça $2,08 \mathrm{~mm}$ e do metasoma $2,08 \mathrm{~mm}$; comprimento do olho $1,36 \mathrm{~mm}$; distância interorbital superior $1,28 \mathrm{~mm}$ e a inferior $0,98 \mathrm{~mm}$.

Alótipo fêmea. Tegumento da cabeça preto com larga estria amarela quase até o ápice das paroculares, inferiormente acompanhando a sutura epistomal, com recorte arqueado abaixo dos alvéolos antenais e mais estreita no ápice; área posterior do vértice até os cantos superiores das pós-genas amarelo-ferrugínea. Mesosoma preto, mesoscuto com faixas látero-basais amarelas levemente mescladas com ferrugíneo e pouco mais largas para o meio; metade apical das axilas e margem do escutelo amarelos com orla translúcida acastanhada clara. Tégulas castanho-ferrugíneas: asas escurecidas e veias enegrecidas. Pernas enegrecidas somente até a área basal do fêmur e no restante amarelo-ferrugíneas. Tergos pretos, o basal com larga faixa discal amarela, alargando nos flancos onde quase chega até a margem; terceiro tergo também com faixa amarela discal, com o bordo anterior levemente bisinuado e muito estreita nos cantos.

Pilosidade difere da do macho pelas cerdas acastanhadas da metade dorsal da cabeça. Escopa ventral cremosa.

Comprimento aproximado 5,42 mm; (asa quebrada); largura da cabeça $2,24 \mathrm{~mm}$ e do metasoma $2,24 \mathrm{~mm}$; comprimento do olho $1,56 \mathrm{~mm}$; distância interorbital superior $1,38 \mathrm{~mm}$ e a inferior $1,18 \mathrm{~mm}$.

Holótipo macho, 19-XI-70, Córdoba, Córdoba, Argentina, M. A. Fritz leg. Alótipo fêmea, I-62, Carlos Paz, Córboda, Argentina, R. J. Llano leg.; e dois parátipos, um macho e uma fêmea, II-1926, Paso de los Funes, San Luis, Argentina, sem indicação de coletor. Depositados na Coleção de Entomologia 
Pe. J.S. Moure, Departamento de Zoologia da Universidade Federal do Paraná.

Variações. Exemplar macho de S.Luis com área preta junto à sutura subantenal tão larga como a estria interalveolar e ligada à base do clípeo onde é contínua com uma mancha estreita basal de contorno circular que se estende nos lados quase até a metade da sutura epistomal e termina em linha reta.

Distribuição geográfica. Argentina: Córdoba e S. Luis.

\section{Ctenanthidium bifasciatum, sp.n.}

Diagnose. Fêmea com o tegumento do mesosoma inteiramente preto; mancha amarela parocular curta, nódoas amarelo-ferrugíneas nos cantos do vértice e somente duas faixas amarelas discais completas nos tergos (no primeiro e terceiro). Tegumento do mesoscuto fosco, os espaços entre os pontos micro-reticulados; escutelo e mesepisternos também com micro-reticulação porém brilhantes.

Holótipo fêmea. Tegumento preto com estria amarela parocular terminando na altura da base dos alvéolos antenais; nódoas amarelo-ferrugínas nos cantos do vértice e adjacências das pós-genas; antenas com os cinco artículos basais amarelo-ferrugíneos por baixo, o escapo, pedicelo e os três flagelômeros basais castanhos por cima. Mesosoma preto, escutelo sem área translúcida distinta; tégulas amarelo-ferrugíneas. Pernas anteriores com o fêmur e os tarsômeros menores amarelo-ferrugíneos; nas medianas só parte das tíbias desta cor, restante enegrecido. Asas com tinte enegrecido, veias enegrecidas. Tergos pretos, o basal com faixa amarela discal larga, mais estreita no meio e quase até o bordo nos lados; no segundo somente pequenas nódoas laterais amarelas; terceiro com faixa amarela discal larga, mais afastada do bordo no meio e aproximando-se do mesmo nos lados, em ângulo muito aberto.

Pilosidade branca, com cerdas acastanhadas na metade dorsal da cabeça, mais curtas no mesoscuto e escutelo; escopa ventral branca.

Comprimento aproximado $6,75 \mathrm{~mm}$; comprimento da asa $5,33 \mathrm{~mm}$; largura da cabeça $2,20 \mathrm{~mm}$ e do metasoma $2,36 \mathrm{~mm}$; comprimento do olho $1,52 \mathrm{~mm}$; distância interorbital superior $1,48 \mathrm{~mm}$ e a inferior $1,16 \mathrm{~mm}$.

Holótipo fêmea, 31-I-1992, La Estanzuela, Colonia, Uruguai, Laroca e Varela leg. Deposidado na Coleção de Entomologia Pe. J.S. Moure, Departamento de Zoologia da Universidade Federal do Paraná.

Distribuicão geográfica. Uruguai: Colonia, La Estanzuela.

\section{Ctenanthidium nigripes, sp.n.}

Diagnose. Fêmea com mancha amarela das paroculares até pouco acima dos alvéolos antenais; com nódoa amarela nos cantos do vértice; pernas enegrecidas,sem áreas ferrugíneas; primeiro e do terceiro ao quinto tergo com 
faixa amarela discal, interrompida no quarto. Tegumento micro-reticulado nos intervalos entre os pontos do mesoscuto, porém brilhante.

Holótipo fêmea. Tegumento preto com nódoas amarelas nos cantos do vértice e nas paroculares inferiores, nestas acompanhando a sutura epistomal e com o bordo bisinuado para o dorso terminando pouco acima dos alvéolos antenais. Mesosoma preto; mesoscuto com faixas basais amarelas dos lados, pouco alargadas para o meio; metade apical das axilas e faixa apical amarela no escutelo, ambos com orla translúcida acastanhada clara. Tégulas castanho-ferrugíneas; asas escurecidas e veias enegrecidas. Pernas enegrecidas. Tergo basal com larga faixa amarela discal, pouco mais estreita no meio, alargando muito para os flancos e quase chegando até a margem; no segundo com pequenas nódoas amarelas nos cantos; terceiro com faixa amarela discal larga, o bordo anterior levemente bi-sinuado e estreita nos cantos; quarto com faixa discal amarela pouco mais estreita que as anteriores, interrompida no meio e muito estreitada nos lados; quinto com faixa amarela mais curta não chegando aos lados porém não interrompida: restante preto.

Pilosidade branca predominando, acastanhada e lisa na fronte e vértice, mesoscuto e escutelo; escopa ventral esbranquiçada.

Comprimento aproximado $6 \mathrm{~mm}$; comprimento da asa $5,42 \mathrm{~mm}$; largura da cabeça $2,04 \mathrm{~mm}$; do metasoma $2,04 \mathrm{~mm}$; comprimento do olho $1,40 \mathrm{~mm}$; distância interorbital superior $1,34 \mathrm{~mm}$ e a inferior $1,08 \mathrm{~mm}$.

Holótipo fêmea, 19-XI-1966, Casa Grande, Potosi, Bolivia, H.Blanchard leg. Depositado na Coleção de Entomologia Pe. J.S. Moure, Departamento de Zoologia da Universidade Federal do Paraná.

Distribuição geográfica. Bolívia: Potosi, Casa Grande.

AGRADECIMENTOS. A autora agradece ao Prof. Dr. Pe. Jesus Santiago Moure pelo nome dado ao gênero.

\section{REFERÊNCIAS BIBLIOGRÁFICAS}

MICHENER, C.D. 1948. The Generic Classification of the Anthidiine bees (Hym., Megachilidae). Amer. Mus. Novit. 1381: 1-29.

Recebido em 20.I.1992; aceito em 28.II.1993. 